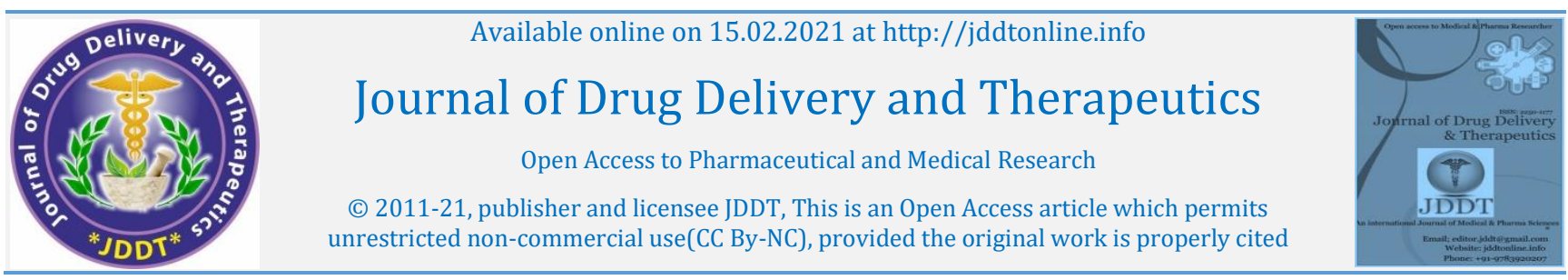

Open Access Full Text Article

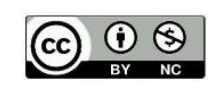

Review Article

\title{
An Overview on Biomaterials: Pharmaceutical and Biomedical Applications
}

\author{
Naidu Nikita*, Wadher Kamlesh, Umekar Milind \\ Department of Pharmaceutics, Smt. Kishoritai Bhoyar College of Pharmacy, Kamptee, Nagpur, Maharashtra, India 441002
}

\begin{tabular}{l}
\hline Article Info: \\
Article History: \\
Received 23 Nov 2020; \\
Review Completed 08 Jan 2021 \\
Accepted 16 Jan 2021; \\
Available online 15 Feb 2021
\end{tabular}

Cite this article as:

Naidu N, Wadher K, Umekar M, An Overview on Biomaterials: Pharmaceutical and Biomedical

Applications, Journal of Drug Delivery and Therapeutics. 2021; 11(1-s): 154-161

DOI: http://dx.doi.org/10.22270/jddt.v11i1-s.4723

\begin{abstract}
The development of biomaterials has existed from around half a century and manifests its use in different fields. Biomaterials are used in living creature body, looking on its biocompatibility nature. In recent years, advances of biomaterials are showing a marked presence in the fast growing fields of pharmaceuticals and medicines. According to their availability, different types of biomaterials like metal, ceramic, polymer and their composites are used for several purposes in the body. In this review article, types of biomaterials have been discussed with their advantages, disadvantages and recent applications in the pharmaceutical field such as implants used to mimic the structure and function of tissues, dental implants, wound healing, cell regeneration, regenerative medicines, delivery of drugs and different organ regeneration. Organ regeneration leading to replacement of organs such as heart, trachea and lungs etc. by use of specific biomaterials has been reported with the diagnosis of diseases and its treatment.
\end{abstract}

Keywords: Biomaterial, Polymers, Pharmaceutical applications, Tissue engineering, Drug delivery.

*Address for Correspondence:

Nikita Naidu, Department of Pharmaceutical Technology, Smt. Kishoritai Bhoyar College of Pharmacy, Kamptee, Nagpur, Maharashtra, India 441002

\section{INTRODUCTION}

From the last few decades, biomaterials have marked its presence in the fast advancing pharmaceutical and medical fields. Biomaterials are those materials which are intended to interact with biological living tissue and used for therapeutic and diagnostic purpose. Earlier these materials were only used in medical devices to treat or to replace any tissue or improve the functions of organ. But later it was found that the term non-viable given to them is inappropriate as biomaterials have its application more than just as implanted devices. ${ }^{1}$ Biomaterials are a major part of our routine practice in the diagnosis as well as for the treatment of several human diseases. ${ }^{2}$ Biomaterials are basically, any materials (Natural or synthetic) that are biologically compatible with the human body and is used to support, enhance, restore or replace the biological function of damaged tissues and is continuously in contact with the body fluids.

\section{BASIC FEATURES REQUIRED FOR THE BIOMATERIAL:}

Since the biomaterials are in direct contact with the body tissues and body fluid, there are some basic features required for the biomaterial such as biocompatibility, inertness, safety, stability, cost effective and easy to fabricate $^{3}$ as shown in figure 1

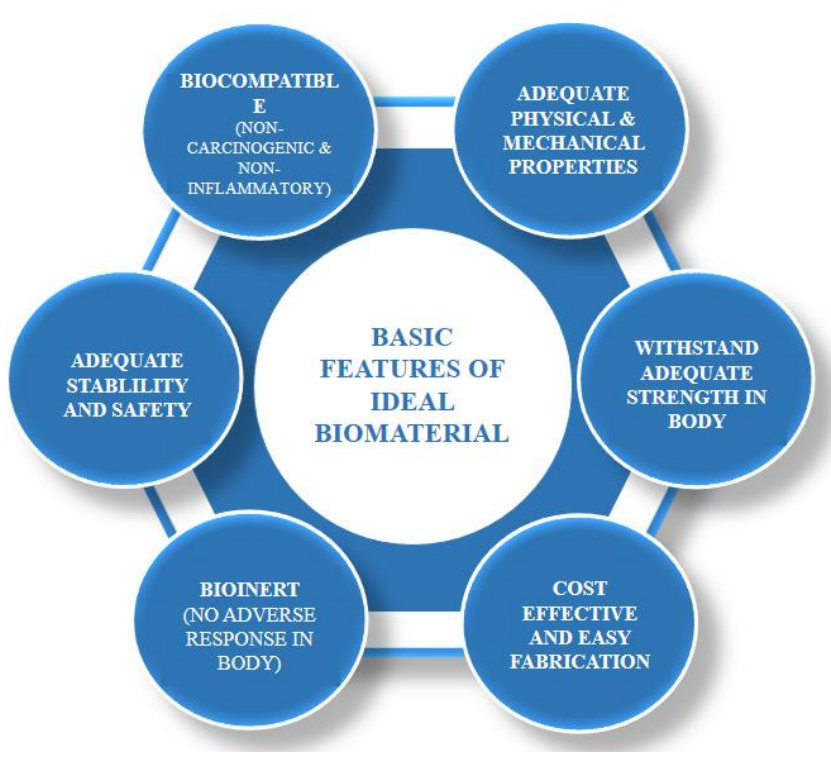

Figure 1: Features of Biomaterials

\section{CLASSIFICATION OF BIOMATERIALS 4}

Biomaterials can be broadly classified on the basis of its source, such as natural and synthetic biomaterial which can also be further sub-classified as shown in table $\mathbf{1}$ and figure 2. 
Table 1: Classification based on occurrence of biomaterials

\begin{tabular}{|l|l|}
\hline \multicolumn{2}{|c|}{ Biomaterials Naturally extracted biomaterials } \\
\hline \multicolumn{2}{|c|}{ Example } \\
\hline Protein based biomaterials & Collagen, fibrin, and silk \\
\hline Polysaccharide based biomaterials & Chitosan (CS), alginate, and hyaluronan. \\
\hline Gum based biomaterials & Pectin, xanthum gum, dextran \\
\hline \multicolumn{2}{|c|}{ Synthetically derived biomaterials } \\
\hline Polymer-based biomaterials & PLGA and polyethyleneglycol (PEG) \\
\hline Peptide-based biomaterials & short amino acids and self-assembling peptides \\
\hline Ceramic-based biomaterials. & \\
\hline
\end{tabular}

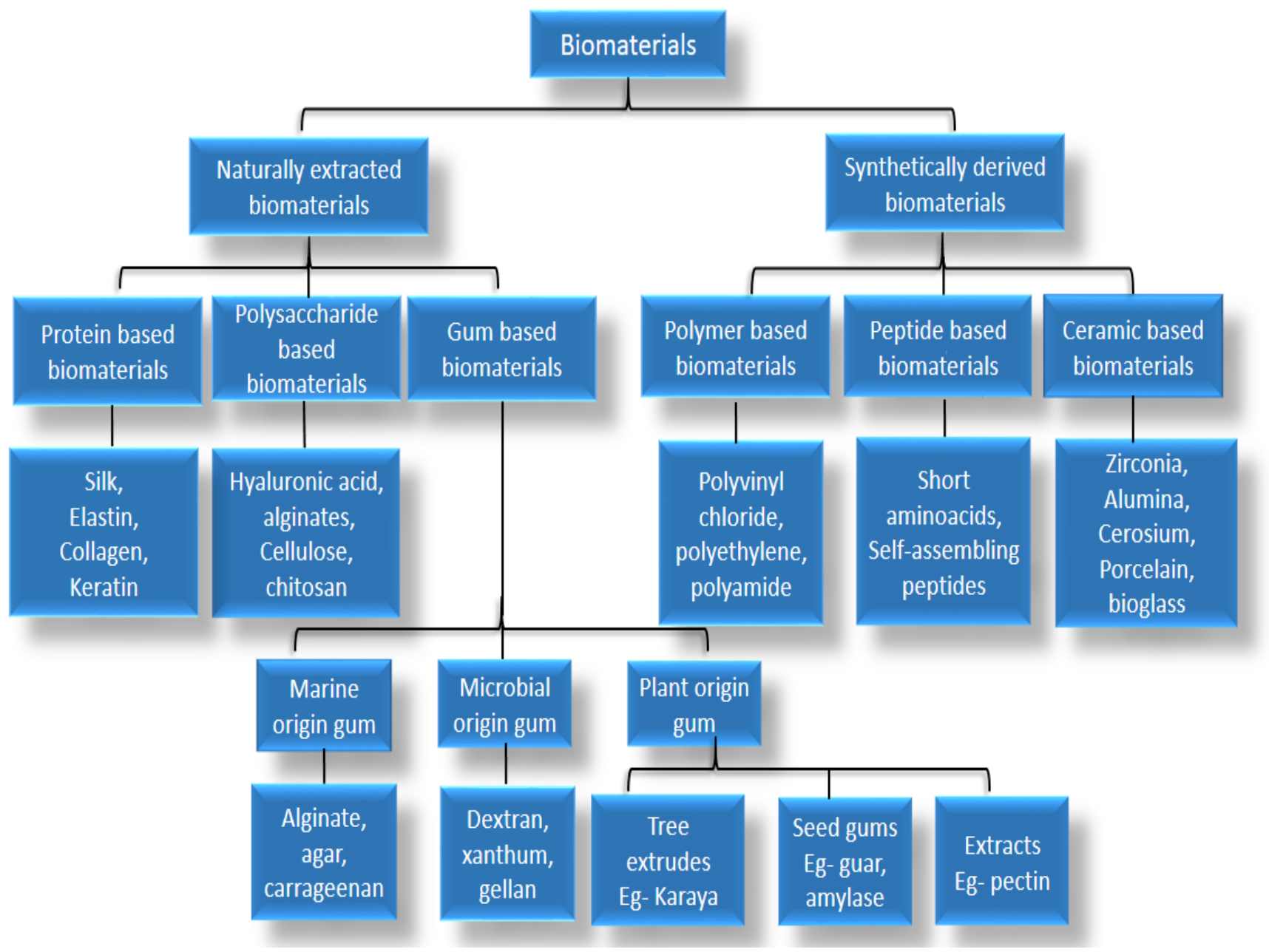

Figure 2: Classification of biomaterials

\section{MATERIALS USED AS BIOMATERIALS}

Ceramics, metals, polymers and composites can be used for constructing biomaterials which can be further engineered with biochemical, biophysical or biomechanical signals according to the expected demands. ${ }^{4}$

\section{CERAMICS}

Ceramics are biocompatible materials also known as bioceramics. Bio-ceramics are generally firm materials for the surgical implants whereas some are flexible. Bio-ceramics are either the long durable metal oxides or are the body's own materials. The average range of duration have raised because of the continuous innovation in the biomaterial field. ${ }^{5}$

In 1950s, it was found that the inert ceramic materials are used for the structural bone replacement because of their biocompatibility and also mechanical properties. In 1980s, it was found that ceramic materials like glass-ceramic, bioactive glasses, calcium sulphates and phosphates are used as bone grafts or for the metallic implants coatings because of their degradation behavior. Later, a ceramic scaffold for hosting cells and bioactive molecules for the bone tissue regeneration was also found to be effective. The 
synthesis of the implantable scaffolds is able to provide a long-term antibiotics delivery. ${ }^{6}$

Bio-ceramic materials are used as biomimetic systems and they are designed to meet the mechanical and biophysical properties followed with the similar structure of the original tissue. These systems are deliberated for getting similar functions as that of original tissues but for more improvement in the performance, therapeutic molecules can be integrated within. ${ }^{7}$ The biomimetic ceramics provides enhanced protein absorption and can be used to load therapeutic molecules. Some of the biomimetic ceramics are also used as therapeutic molecule for example glass is used for antibacterial activity. ${ }^{8}$

Ceramics can be classified as nonabsorbable/ inert (Alumina, zirconia, silicone nitrides, and carbons) and absorbable/ non-inert (calcium phosphates and calcium aluminates). There are different generations of bioceramic materials and each of them includes some specific type of material as depicted in table 2.

Table 2: Types of bioceramic material ${ }^{6}$

\begin{tabular}{|c|c|}
\hline Types of bioceramic material & Examples \\
\hline First generation & Alumina: $\mathrm{Al}_{2} \mathrm{O}_{3} \mathrm{Zirconia}: \mathrm{ZrO}_{2}$ Carbons. \\
\hline Second generation & $\begin{array}{c}\text { Calcium phosphates, Calcium sulphate, Calcium phosphates and } \\
\text { sulfates+ZnO, } \mathrm{Fe}_{2} \mathrm{O}_{3}, \mathrm{CaCO}_{3}, \text { Hydroxyapatite, Glasses, Glass ceramics. }\end{array}$ \\
\hline Third generation & $\begin{array}{r}\text { Bioglass: Porous bioactive and biodegradable ceramics, Mesoporous } \\
\text { materials, organic-inorganic hybrids }\end{array}$ \\
\hline
\end{tabular}

\section{POLYMERS}

Polymers are the mainstays developed for the delivery of therapeutic drugs. ${ }^{9}$ Polymeric materials have a wide application in biomedical field as the polymers can degrade into metabolites of body or are eliminated from the body. Polymeric biomaterials have been monitored for biochemical, biotechnological, medical as well as pharmaceutical applications. ${ }^{0,11}$

Table 3: Types of polymeric materials

\begin{tabular}{|c|c|}
\hline Polymeric material & Examples \\
\hline Natural polymers & Fibrin, chitosan, carrageenan, collagen, alginate, hyaluronate \\
\hline Synthetic polymers & Acrylics, polyamides, polyesters, polysiloxanes, polyurethane \\
\hline
\end{tabular}

Different approaches are utilized for the synthesis of different polymers. Polymeric scaffolds are used for the replacement of different injured tissues (hard and soft tissues). For hard tissue engineering, the use of polymeric substitutes is less because of the poor mechanical properties. Thus cross-linking through chemical reactions are done for improving the mechanical properties. ${ }^{12}$

To provide with controlled drug delivery, bioactive agents or the drugs are entrapped inside the matrix which is insoluble and have very small dimensions in the range of sub-nano, nano or micro. Polymeric materials are most commonly used as matrix for the controlled release of the therapeutic agents. ${ }^{13}$ The ideal properties required for a biodegradable polymer should be, better incorporation of drugs, specific drug targeting, controlled release of drug, greater stability, maximum distribution, reduction in toxicity while maintaining the therapeutic activity. ${ }^{11}$

\section{Natural polymers}

Agarose is a marine polysaccharide derived from red seaweed and has so many beneficial properties such as high bioactivity, thermo gelling behavior, and switchable chemical reactivity for functionalization. Thus agarose is used for the construction of several drug delivery systems as a carrier for the therapeutic drug. ${ }^{14,15}$

Alginate is one of the most commonly used biomaterials obtained from brown algae, commonly Laminaria hyperborean, Laminaria digitate, Laminaria japonica, Ascophyllum nodosum, and Macrocystis pyrifera. ${ }^{16}$ Nanocellulose has shown great promise due to its robust mechanical properties, and desirable biological characteristics. ${ }^{17}$

Pectin derived from plant cell walls is an ideal candidate for hydrogel formation and 3D bioprinting on account of its high molecular weight, and hydrophilicity. Fucoidan, watersoluble polysaccharide derived from marine brown algae. Starch is a polysaccharide derived from cereals and tuber plants. ${ }^{18}$

Collagen is used as a biomaterial for making scaffolds for wound healing. It is generally used for skin wound healing as it has great abundance in the body as it is the main component of the dermal extracellular matrix. ${ }^{19}$

Chitin and chitosan derivatives are the polymeric materials used for different purpose such as excipient, drug carrier, and oral mucoadhesive, water resistant adhesive by virtue of their release characteristics and adhesion. ${ }^{20}$

\section{Synthetic polymers}

Polyesters are thermoplastic polymers and these can be developed from a variety of monomers by ring opening and condensation polymerization routes depending on the monomeric units. Different synthetic routes are available for developing polyesters. ${ }^{21}$ Polyglycolide is a synthetic polymer investigated for biomedical applications. It is highly crystalline polymer and thus exhibits a high tensile modulus with low solubility in organic solvents. It shows excellent mechanical properties due to its high crystallinity. Polyglycolide is very stiff in comparison to other biodegradable polymeric system used clinically. ${ }^{22}$ 
Polycarbonatesare, a class of synthetic polymers. They are a group of thermoplastic polymers which contains carbonate groups in their structure. Aliphatic carbonates becomes soft in the temperature range $40-50^{\circ} \mathrm{C} .{ }^{23}$

Polyethylenes are thermoplastic and have crystalline structure. It is defined as a polymer of ethylene produced by addition polymerization, linear polymers and also prepared by condensation reactions. ${ }^{24}$ Polyphosphazene-based biomaterials are a newly developed biomaterial used in biomedicine. This is a distinctive class of polymers which have exceptional benefits that are rarely found in the polymers like poly( $\varepsilon$-caprolactone) and poly(lactic-coglycolic acid. Although the complete use of the polymer is not accomplished but has found promising characteristics for tissue engineering as well as drug delivery. ${ }^{25}$

\section{METALS}

Metallic implants have great importance in the medical field. Metallic biomaterials are preferred because of the mechanical properties, biocompatibility, low friction, low cost and resistance to corrosion. ${ }^{26}$ But these are highly aggressive to microenvironment that can lead to metal degradation and release of unwanted metallic ions which can cause local tissue damage and inflammation. ${ }^{27}$ Steels, stainless steel, titanium alloys, cobalt chromium alloys, gold, and gold alloys are the most common metallic biomaterials.

Metallic biomaterials have different intrinsic properties like toughness, high strength, and electrical conductivity, mechanical reliability, corrosion resistant and wear resistant. These properties of metallic biomaterials make the medical metal devices make metals more dominating than other materials. It is found that nearly $70-60 \%$ of the implants made are of metal. ${ }^{28}$
Some metallic elements which occur in natural form are essential for red blood cells function iron or synthesis of vitamin B-12 but cannot be tolerated in large amount in the body. Thus the biocompatibility of the metallic biomaterials is very important concern as they can corrode in an in vivo environment. ${ }^{29}$ Zinc as a metal biomaterial exhibits various intrinsic physiological relevance, biocompatibility, biodegradability. Zinc ceramic nanomaterials are used for tissue engineering, drug delivery and also cancer therapy. ${ }^{30}$

\section{COMPOSITES}

The word "composite" refer to the materials in which the definite phases are divided on a larger scale than the atomic, and the elastic modulus properties can be altered. Some of the natural composites are wood, bone, dentin, skin and cartilage. Foam as a composite has one of the phase empty. Natural foams are lung, cancellous, bone and wood. ${ }^{31}$ Composite as a biomaterial has application for orthopedic implants, dental filling composites, and bone cements. ${ }^{29,32}$ Composites are generally stronger from any of the single materials from which they are made. Composites have advantages in comparison to the metals and ceramics as they have disadvantage like low bioavailability and corrosion of metals. Recently various types of different composite materials for biomedical application are developed it is becoming one of the preferred choice for load bearing tissue components. The composite biomaterials has advantages like great biocompatibility, no corrosion as in metals and fracture strength in comparison to ceramic materials. 33

The advantages, disadvantages and applications of various types of biomaterials are depicted in table 4.

Table 4: Advantages, Disadvantages and Applications of various types of biomaterials

\begin{tabular}{|l|l|l|l|}
\hline $\begin{array}{l}\text { Types of } \\
\text { biomaterials }\end{array}$ & Advantages & Disadvantages & Applications \\
\hline Ceramics & $\begin{array}{l}\text { Inert, corrosion resistance, high } \\
\text { biocompatibility, low thermal } \\
\text { and electrical conductivity. }\end{array}$ & $\begin{array}{l}\text { Difficult manufacturing, low } \\
\text { impact strength, } \\
\text { reproducibility. }\end{array}$ & $\begin{array}{l}\text { Surgical implants, dental parts, } \\
\text { Coatings, structural bone } \\
\text { replacement, medical } \\
\text { equipment, bone fillings and } \\
\text { bone tissue regeneration. }\end{array}$ \\
\hline Polymers & $\begin{array}{l}\text { Easy to Fabricate, low frictional } \\
\text { properties. }\end{array}$ & Low mechanical resistance. & $\begin{array}{l}\text { Implants, replacement of } \\
\text { tissues, eye lenses, Sutures, } \\
\text { artificial tendons. }\end{array}$ \\
\hline Metals & $\begin{array}{l}\text { Ductility, high Mechanical } \\
\text { resistance, low friction, low cost }\end{array}$ & $\begin{array}{l}\text { Low biocompatibility and } \\
\text { resistance to corrosion in } \\
\text { physiological environment, } \\
\text { mechanical properties are } \\
\text { different from biological tissues. }\end{array}$ & $\begin{array}{l}\text { Joint prostheses, dental } \\
\text { implants. }\end{array}$ \\
\hline $\begin{array}{l}\text { Bio- } \\
\text { composites }\end{array}$ & $\begin{array}{l}\text { Inert, corrosion resistant, } \\
\text { superior biocompatibility. }\end{array}$ & $\begin{array}{l}\text { Difficult to reproduce during } \\
\text { fabrication. }\end{array}$ & $\begin{array}{l}\text { Heart valves, implants, knee } \\
\text { implants and artificial joints. }\end{array}$ \\
\hline
\end{tabular}




\section{APPLICATIONS OF BIOMATERIALS}

Bio materials are having numerous pharmaceutical and medical applications such as for organ regeneration, drug delivery, tissue engineering etc. and are shown in figure 3:-

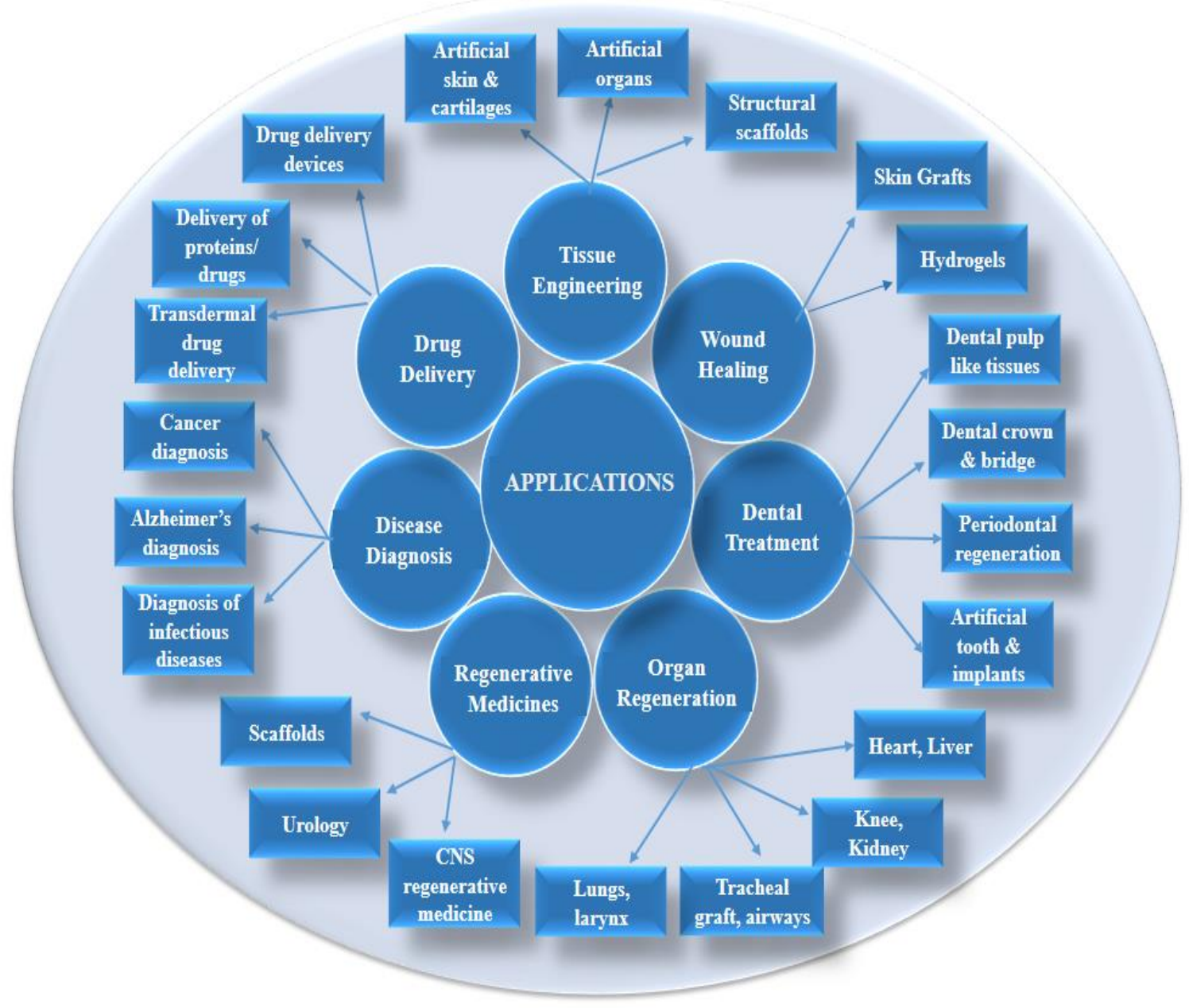

Figure 3: Applications of biomaterials

\section{DENTAL APPLICATION}

Biomaterials have its application in dentistry as well; materials like resin composites, and titanium alloys, zirconia etc. are used as dental biomaterials. Dental pulp-like tissues can be engineered and a complete tooth can be engineered. Tissue engineering for the tissue replacement by using cultured cells and seeded them on synthetic extracellular matrices as a biomaterial can be used. Ultimately it was found that tooth engineering can be done. ${ }^{34}$ For root canal infections biomaterials like chitosan or gelatin for sustained release of calcium hydroxide was used by formulating the nanoparticles. ${ }^{35} \mathrm{~A}$ protein based biomaterial i.e. enamel matrix derivative was used for the process of periodontal regeneration. Enamel matrix derivatives are also used to increase the expression of markers for odontoblasts and odontoblast-like-cells present in the human dental pulpal tissue. ${ }^{36}$ Dental tissue regeneration can be done by injectable biomaterials scaffolds. ${ }^{37}$ By fabricating nanoparticles from polymeric biomaterials, various dental problems can be cured. 38

\section{ORGAN REGENERATION}

Heart- Development of biocompatible cardiac patch was done by adhering the stem cells to the biomaterials and then transplanted. It has been reported that cardiomyocytes embedded in hydrogel patches shows contractile properties and mechanical stimulation. 39,40

Lungs- lungs have been regenerated ex vivo by seeding of the pulmonary epithelium and vascular endothelium on rat decellularized scaffolds. ${ }^{41}$

Knee- To avoid the aseptic loosening while complete knee replacement surgery and also to improve the performance of bone prosthesis system, the two types of ceramic based functional biomaterials were proposed. Alumina based functionally graded and zirconia based functionally graded biomaterials showed good performance. ${ }^{42}$

Tracheal graft- Tracheal epithelial graft made from different biomaterials (HyaluronanPoly(Ethylene Glycol), Chitosan-Collagen, Collagen Vitrigel Membrane, Fibrin Glue, Silk Fibroin, and Gelatin) have been developed. This was beneficial for the airway related diseases. ${ }^{43}$

Liver, kidney, airways, tracheal and larynx replacement by biomaterials can be developed by engineering the organs. ${ }^{44}$

\section{REGENERATIVE MEDICINES}

Regenerative medicines provides as substitute for tissues lost due to some reasons like disease, trauma or any other abnormalities. ${ }^{45}$ Regenerative medicine combines tissue 
engineering and drug delivery, and uses multidisciplinary principles of medicine, material science and life science to generate better biological structure and functions of tissues and organs. Regenerative medicine is for implanting scaffold materials for regenerating tissues. Cell scaffolds have a major role because they act as artificial extracellular matrix and provides a temporary environment to support the cell. ${ }^{46}$

Biomaterials and regenerative medicine are developing in urology as well. Regenerative urology was firstly used for the repair of small urinary tract segments and now has reached to a level of 3D templates for totally functional organs. ${ }^{47}$ Hyaluronic acid is the main component of the brain extracellular matrix and is used as CNS regenerative medicines because it has great role in the study and treatment of CNS disorders. The biological activity and the chemical modification of hyaluronic acid helps for creating customized and versatile scaffolds for CNS tissue engineering and regenerative medicine. 48

\section{TISSUE ENGINEERING}

Construction of scaffolds is the main step for successful tissue engineering to occur. The material used for the construction must be considerable. Different natural as well as synthetic polymers can be used for the construction of the scaffolds. Electrically conductive polymers in combination with some other polymers can be used to apply the electric fields during tissue engineering and thus results for superior biological and physiological features. ${ }^{49}$

Electrospun nanofibers are used in several tissue engineering fields. Electrospinning is not a technique for scaffold production but by combining the method with 3D printing it can be used for the production of electrospun nanofiber as a biomaterial and it can easily deliver the cell stimulatory agents. 50

Artificial organs are formed by tissue engineering techniques. For a particular development, biomaterials of specific form according to the design of material, which includes the pore size and degradation kinetics, also the functionalization with cell and tissue specific factors, the intrinsic factors of the tissue constructs can be controlled to increase the remodeling and functional outcomes. 51

\section{WOUND HEALING}

For wound healing, silk grafts were made by using silk as a biomaterial for healing process. ${ }^{52,} 53$ Different biomaterials can be used for wound dressings and wound repair by making nanofibers from electro-spinning method. ${ }^{54}$ It is proven that biomaterials having antioxidant property can increase the chronic wound healing property. ${ }^{55-59} \mathrm{~A}$ bioactive glass composite biomaterial are used for wound healing process. ${ }^{60}$ Chitin and chitosan have a great role as a biomaterial for the wound healing. ${ }^{61} \mathrm{By}$ using the graft copolymerization, magnetic composite hydrogel was developed for guaifenesin with the help of itaconic acid on starch and alginic acid in presence of grapheme sheets and Fe304 nanoparticles and this was useful for wound healing and drug delivery. ${ }^{62}$ Protease modulating matrix products have shown potential for the treatment of chronic wounds. 63

For wound healing, hydrogel acts as a great candidate as they can form a barrier from the hydrated environment and the pathogens. Polyvinyl alcohol is generally used for the fabrication of hydrogel and it shows application for wound healing. ${ }^{64}$ Calcium alginate hydrogel has provided as a drug carrier for protamine with neovascularization function in chronic wounds treatment. ${ }^{65}$ Hyaluronan a polysaccharide is present in the skin and shows a great use as a hydrogel for wound healing. Hyaluronan with chitosan is used for the delivery of angiogenic promoting growth factor i.e. vascular endothelial growth factor and its shows antibacterial and angiogenic activity and will show wound healing. 66

\section{DRUG DELIVERY}

The expeditious development of science and technology has led the application of biomaterials in different fields of biology, physics, chemistry, tissue engineering as well as medicine. ${ }^{67,68}$ From last 50 years, Biomaterials have been researched and used in pharmaceutical drug delivery and found to enhanced the delivery and effectiveness of many therapeutic agents along with antibodies, peptides, vaccines and enzymes. ${ }^{69}$

An-Yong Cai et. al has reported that biomaterials have a huge number of advantages and are used for nanocarriers which have good biocompatibility, good biodegradability, high drug loading capacity and have $\mathrm{pH}$ responsive drug release performance and therefore used for the delivery of drugs. The well-designed drug delivery systems by synthetic bio mineral Nano carriers can help to prevent the prior leakage of drug and protect the drug from inactivation during the circulation. Biomineral based nanocarriers are used for the delivery of chemotherapeutic drugs, genes and proteins. ${ }^{70}$

Nanofibrous biomaterials are used for drug delivery because of their great potential and structural features that are same to extracellular matrix. Different natural as well as polymeric materials can be used to make nanofibrous biomaterials. ${ }^{71}$ The central nervous system (CNS) depends on the state of neural cells and also on various extracellular components which arranges the cellular behaviour into proper tissue functions. Biomaterials have a crucial role in regaining or increasing the role of extracellular components in CNS for the event of injury and disease. Biomaterials are also used for cell transplantation as well as for the delivery of proteins or drug. ${ }^{72}$

The components derived from extracellular matrix are emerging as origin of biomaterials for engineering, which are able to induce desired cell- specific response. Hao Xing et al have reported the use of various biomaterials that are derived from naturally available extracellular matrix proteins for regulating the cell function. ${ }^{73}$ Marco Corti et al have developed patches from polyacrylate as a biomaterial for the transdermal drug delivery through the high internal phase emulsion technique for the wound healing. ${ }^{74}$ HanSeong Kim et al have developed atenolol imprinted polysaccharide biomaterial by using mungbean starch and polyvinyl alcohol and evaluated them for drug release behavior. 75

\section{OTHER APPLICATIONS}

Nanoscale metal- organic frameworks have a clinical application for treatment of cancer and also for disease diagnosis. Thus, multifunctional nanoscale metal organic framework based nanoplatform was developed for the diagnosis of Alzheimer's disease and therapy. ${ }^{76}$ Radiation therapy is used to treat cancer but it has some side effects, using biomaterials in combination with radiation and chemotherapy leads to safer and effective delivery of therapy. Biomaterials have restructured in the field of diagnostic imaging, and are also transfiguring in the theranostics, combinational therapy and also tissue protection. ${ }^{77}$

Non-biodegradable biomaterials as hydrogel implants can be used for enabling the sustained release of anti-vascular endothelial growth factors and also for having preserved bioactivity in vivo. Anti-vascular endothelial growth factors 
has now become the most preferable treatment modality for various retinal diseases. ${ }^{78}$ Poly-dopamine/Hyaluronic acid coatings were prepared on the $\mathrm{NaOH}$ passivated $\mathrm{Mg}-\mathrm{Zn}-\mathrm{Y}-\mathrm{Nd}$ alloy for the application as cardiovascular implants. ${ }^{79}$ Cryogel/hydrogel biomaterials have shown functional effects of absorption, immunomodulation and antimicrobial activity to the diabetic skin wounds. ${ }^{80}$

\section{CONCLUSION:}

Biomaterials can be the multidisciplinary of all the fields. Since its inception, they have been showing great application in medical and pharmaceutical field. Different types of biomaterials are used for specific purpose in the body. Several biomaterials are used as implants to mimic the structure and function of tissues/organs, organ regeneration, tissue engineering, wound healing, diagnosis of diseases and treatment, and delivery of drugs. Recently biomaterials are showing application in urology and cell regeneration as well. Different drug delivery scaffolds, nanocarriers are exhibiting a great role for the delivery of drugs. Biomaterials are emerging a substantial role in the pharmaceutical and medical field.

Acknowledgements: The authors are thankful to the faculties of Smt. Kishoritai Bhoyar College of Pharmacy for guiding the preparation of this manuscript.

\section{Conflict of Interest: There are no conflicts of interest}

\section{REFERENCES:}

1. Ghasemi-Mobarakeh L, Kolahreez D, Ramakrishna S, Williams D. Key terminology in biomaterials and biocompatibility. Current Opinion in Biomedical Engineering. 2019; 10:45-50.

2. Kargozar S, Ramakrishna S, Mozafari M. Chemistry of biomaterials: Future prospects. Current Opinion in Biomedical Engineering. 2019; 10:181-90.

3. Nair LS, Laurencin CT. Biodegradable polymers as biomaterials. Progress in polymer science. 2007; 32(8-9):762-98.

4. Wang J, Yu Y, Guo J, Lu W, Wei Q, Zhao Y. The Construction and Application of Three-Dimensional Biomaterials. Advanced biosystems. 2020;4(2):1900238.

5. Kaur G. Biomaterials influencing human lives. InBioactive glasses 2017 (pp. 1-20). Springer, Cham.

6. Regi MV, Esbrit P, Salinas AJ. Degradative Effects of the Biological Environment on Ceramic Biomaterials. InBiomaterials Science 2020 (pp. 955-971). Academic Press.

7. Zwingenberger S, Nich C, Valladares RD, Yao Z, Stiehler M, Goodman SB. Recommendations and considerations for the use of biologics in orthopedic surgery. BioDrugs. 2012; 26(4):24556.

8. Fernandes JS, Gentile P, Pires RA, Reis RL, Hatton PV. Multifunctional bioactive glass and glass-ceramic biomaterials with antibacterial properties for repair and regeneration of bone tissue. Acta biomaterialia. 2017; 59:2-11.

9. Asadpour S, Yeganeh H, Ai J, Ghanbari H. A novel polyurethane modified with biomacromolecules for small-diameter vascular graft applications. Journal of Materials Science. 2018; 53(14):9913-27.

10. Leja K, Lewandowicz G. Polymer biodegradation and biodegradable polymers-a review. Polish Journal of Environmental Studies. 2010; 19(2).

11. Roy SM, Sahoo SK. Controlled drug delivery: polymeric biomaterials for. Encyclopedia of Biomedical Polymers and Polymeric Biomaterials. 2015; 11:2135-46.

12. Oryan A, Kamali A, Moshiri A, Baharvand H, Daemi H. Chemical crosslinking of biopolymeric scaffolds: Current knowledge and future directions of crosslinked engineered bone scaffolds. International journal of biological macromolecules. 2018; 107:678-88.

13. Wadher KJ, Kakde RB, Umekar MJ. Study on sustained-release metformin hydrochloride from matrix tablet: Influence of hydrophilic polymers and in vitro evaluation. International journal of pharmaceutical investigation. 2011; 1(3):157.

14. Zarrintaj P, Manouchehri S, Ahmadi Z, Saeb MR, Urbanska AM,
Kaplan DL, Mozafari M. Agarose-based biomaterials for tissue engineering. Carbohydrate polymers. 2018; 187:66-84.

15. Yazdi MK, Taghizadeh A, Taghizadeh M, Stadler FJ, Farokhi M, Mottaghitalab F, Zarrintaj P, Ramsey JD, Seidi F, Saeb MR, Mozafari M. Agarose-based biomaterials for advanced drug delivery. Journal of Controlled Release. 2020 .

16. Lee KY, Mooney DJ. Alginate: properties and biomedical applications. Progress in polymer science. 2012; 37(1):106-26.

17. Lin N, Dufresne A. Nanocellulose in biomedicine: Current status and future prospect. European Polymer Journal. 2014; 59:30225.

18. Lu DR, Xiao CM, Xu SJ. Starch-based completely biodegradable polymer materials. Express polymer letters. 2009; 3(6):366-75

19. Davison-Kotler E, Marshall WS, García-Gareta E. Sources of collagen for biomaterials in skin wound healing. Bioengineering. 2019; 6(3):56.

20. Kato Y, Onishi H, Machida Y. Application of chitin and chitosan derivatives in the pharmaceutical field. Current Pharmaceutical Biotechnology. 2003; 4(5):303-9.

21. Okada M. Chemical syntheses of biodegradable polymers. Progress in polymer science. 2002; 27(1):87-133.

22. Törmälä P. Biodegradable self-reinforced composite materials; manufacturing structure and mechanical properties. Clinical materials. 1992; 10(1-2):29-34.

23. Gunatillake P, Mayadunne R, Adhikari R. Recent developments in biodegradable synthetic polymers. Biotechnology annual review. 2006; 12:301-47.

24. Ronca S. Polyethylene. InBrydson's plastics materials 2017 (pp. 247-278). Butterworth-Heinemann.

25. Ogueri KS, Ogueri KS, Allcock HR, Laurencin CT. Polyphosphazene polymers: The next generation of biomaterials for regenerative engineering and therapeutic drug delivery. Journal of Vacuum Science \& Technology B, Nanotechnology and Microelectronics: Materials, Processing, Measurement, and Phenomena. 2020; 38(3):030801.

26. Raghavendra GM, Varaprasad K, Jayaramudu T. Biomaterials: design, development and biomedical applications. InNanotechnology applications for tissue engineering 2015 (pp. 21-44). William Andrew Publishing.

27. Prasad K, Bazaka O, Chua M, Rochford M, Fedrick L, Spoor J, Symes R, Tieppo M, Collins C, Cao A, Markwell D. Metallic biomaterials: Current challenges and opportunities. Materials. 2017; 10(8):884.

28. Festas AJ, Ramos A, Davim JP. Medical devices biomaterials-A review. Proceedings of the Institution of Mechanical Engineers, Part L: Journal of Materials: Design and Applications. 2020; 234(1):218-28.

29. Parida P, Behera A, Mishra SC. Classification of Biomaterials used in Medicine.

30. Su Y, Cockerill I, Wang Y, Qin YX, Chang L, Zheng Y, Zhu D. Zincbased biomaterials for regeneration and therapy. Trends in biotechnology. 2019; 37(4):428-41.

31. Ehrlich H. Biocomposites and mineralized tissues. InBiological Materials of Marine Origin 2015 (pp. 91-210). Springer, Dordrecht.

32. Jockisch KA, Brown SA, Bauer TW, Merritt K. Biological response to chopped-carbon-fiber-reinforced peek. Journal of biomedical materials research. 1992; 26(2):133-46.

33. Dorozhkin SV. Biocomposites and hybrid biomaterials based on calcium orthophosphates. Biomatter. 2011; 1(1):3-56.

34. Bohl KS, Shon J, Rutherford B, Mooney DJ. Role of synthetic extracellular matrix in development of engineered dental pulp. Journal of Biomaterials Science, Polymer Edition. 1998; 9(7):749-64.

35. Farhadian, N., Godiny, M., Moradi, S., Azandaryani, A.H. and Shahlaei, M., 2018. Chitosan/gelatin as a new nano-carrier system for calcium hydroxide delivery in endodontic applications: Development, characterization and process optimization. Materials Science and Engineering: C, 92, pp.540546.

36. Wang Y, Zhao Y, Ge L. Effects of the enamel matrix derivative on the proliferation and odontogenic differentiation of human dental pulp cells. Journal of dentistry. 2014; 42(1):53-9.

37. Haugen HJ, Basu P, Sukul M, Mano JF, Reseland JE. Injectable Biomaterials for Dental Tissue Regeneration. International journal of molecular sciences. 2020; 21(10):3442.

38. Bapat RA, Joshi CP, Bapat P, Chaubal TV, Pandurangappa R, Jnanendrappa N, Gorain B, Khurana S, Kesharwani P. The use of 
nanoparticles as biomaterials in dentistry. Drug discovery today. 2019; 24(1):85-98.

39. Zimmermann WH, Schneiderbanger K, Schubert P, Didie M, Munzel F, Heubach JF, Kostin S, Neuhuber WL, Eschenhagen T. Tissue engineering of a differentiated cardiac muscle construct. Circulation research. 2002; 90(2):223-30.

40. Shimizu T, Sekine H, Yamato M, Okano T. Cell sheet-based myocardial tissue engineering: new hope for damaged heart rescue. Current pharmaceutical design. 2009; 15(24):2807-14.

41. Petersen TH, Calle EA, Zhao L, Lee EJ, Gui L, Raredon MB, Gavrilov K, Yi T, Zhuang ZW, Breuer C, Herzog E. Tissueengineered lungs for in vivo implantation. Science. 2010 ; 329(5991):538-41.

42. Ayatollahi MR, Davari MH, Shirazi HA, Asnafi A. To Improve Total Knee Prostheses Performance Using Three-Phase Ceramic-Based Functionally Graded Biomaterials. Frontiers in Materials. 2019; 6:107.

43. Varma R, Aoki FG, Soon K, Karoubi G, Waddell TK. Optimal biomaterials for tracheal epithelial grafts: An in vitro systematic comparative analysis. Acta biomaterialia. 2018; 81:146-57.

44. Fishman JM, Wiles K, Lowdell MW, De Coppi P, Elliott MJ, Atala A, Birchall MA. Airway tissue engineering: an update. Expert opinion on biological therapy. 2014; 14(10):1477-91.

45. Chung L, Maestas Jr DR, Housseau F, Elisseeff JH. Key players in the immune response to biomaterial scaffolds for regenerative medicine. Advanced drug delivery reviews. 2017; 114:184-92.

46. Sun J, Tan H. Alginate-based biomaterials for regenerative medicine applications. Materials. 2013; 6(4):1285-309.

47. Davis NF, Cunnane EM, Quinlan MR, Mulvihill JJ, Lawrentschuk N, Bolton DM, Walsh MT. Biomaterials and regenerative medicine in urology. Cell Biology and Translational Medicine, 2018; 3:189-98.

48. Jensen G, Holloway JL, Stabenfeldt SE. Hyaluronic Acid Biomaterials for Central Nervous System Regenerative Medicine. Cells. 2020; 9(9):2113.

49. Vandghanooni S, Eskandani M. Natural polypeptides-based electrically conductive biomaterials for tissue engineering International journal of biological macromolecules. 2020; 147:706-33.

50. Doostmohammadi M, Forootanfar H, Ramakrishna S. Regenerative medicine and drug delivery: Progress via electrospun biomaterials. Materials Science and Engineering: C. 2020; 109:110521.

51. Abbott RD, Kaplan DL. Engineering biomaterials for enhanced tissue regeneration. Current Stem Cell Reports. 2016; 2(2):1406.

52. Thurber AE, Omenetto FG, Kaplan DL. In vivo bioresponses to silk proteins. Biomaterials. 2015; 71:145-57.

53. Chouhan D, Lohe TU, Samudrala PK, Mandal BB. In situ forming injectable silk fibroin hydrogel promotes skin regeneration in full thickness burn wounds. Advanced healthcare materials. 2018; 7(24):1801092.

54. Mulholland EJ. Electrospun biomaterials in the treatment and prevention of scars in skin wound healing. Frontiers in Bioengineering and Biotechnology. 2020; 8.

55. Luo JD, Wang YY, Fu WL, Wu J, Chen AF. Gene therapy of endothelial nitric oxide synthase and manganese superoxide dismutase restores delayed wound healing in type 1 diabetic mice. Circulation. 2004; 110(16):2484-93.

56. Zhu Y, Hoshi R, Chen S, Yi J, Duan C, Galiano RD, Zhang HF, Ameer GA. Sustained release of stromal cell derived factor-1 from an antioxidant thermoresponsive hydrogel enhances dermal wound healing in diabetes. Journal of Controlled Release. 2016; 238:114-22.

57. Fan Y, Wu W, Lei Y, Gaucher C, Pei S, Zhang J, Xia X. Edaravoneloaded alginate-based nanocomposite hydrogel accelerated chronic wound healing in diabetic mice. Marine drugs. 2019; 17(5):285.

58. Wu H, Li F, Shao W, Gao J, Ling D. Promoting angiogenesis in oxidative diabetic wound microenvironment using a nanozymereinforced self-protecting hydrogel. ACS central science. 2019; 5(3):477-85

59. Speidel AT, Stuckey DJ, Chow LW, Jackson LH, Noseda M, Abreu Paiva M, Schneider MD, Stevens MM. Multimodal hydrogelbased platform to deliver and monitor cardiac progenitor/stem cell engraftment. ACS central science. 2017; 3(4):338-48.

60. Moura D, Souza MT, Liverani L, Rella G, Luz GM, Mano JF,
Boccaccini AR. Development of a bioactive glass-polymer composite for wound healing applications. Materials Science and Engineering: C. 2017; 76:224-32.61.

61 Nadri S, Mahmoudvand H, Taee N, Anbari K, Beiranvand S. Promethazine and oral Midazolam preanesthetic children medication. Pediatric emergency care. 2020; 36(7):e369-72.

62. Forouzandehdel S, Forouzandehdel S, Rami MR. Synthesis of a novel magnetic starch-alginic acid-based biomaterial for drug delivery. Carbohydrate research. 2020; 487:107889.

63. Jones RE, Foster DS and Longaker MT. Management of chronic wounds. JAMA 2018; 320:1481-2.

64. Kamoun EA, Kenawy ER, Chen X. A review on polymeric hydrogel membranes for wound dressing applications: PVAbased hydrogel dressings. Journal of advanced research. 2017; 8(3):217-33.

65. Wang T, Zheng Y, Shi Y, Zhao L. pH-responsive calcium alginate hydrogel laden with protamine nanoparticles and hyaluronan oligosaccharide promotes diabetic wound healing by enhancing angiogenesis and antibacterial activity. Drug delivery and translational research. 2019; 9(1):227-39.

66. Huang J, Ren J, Chen G, Li Z, Liu Y, Wang G, Wu X. Tunable sequential drug delivery system based on chitosan/hyaluronic acid hydrogels and PLGA microspheres for management of nonhealing infected wounds. Materials Science and Engineering: C. 2018; 89:213-22.

67. Chen Z, Wu J, Wang Y, Shao C, Chi J, Li Z, Wang X, Zhao Y. Photocontrolled healable structural color hydrogels. Small. 2019; 15(37):1903104.

68. Luo Y, Wei X, Huang P. 3D bioprinting of hydrogel-based biomimetic microenvironments. Journal of Biomedical Materials Research Part B: Applied Biomaterials. 2019; 107(5):1695-705.

69. Yun YH, Lee BK, Park K. Controlled Drug Delivery: Historical perspective for the next 8generation. Journal of Controlled Release. 2015; 219:2-7.

70. Cai AY, Zhu YJ, Qi C. Biodegradable Inorganic Nanostructured Biomaterials for Drug Delivery. Advanced Materials Interfaces. 2020; 7(20):2000819.

71. Li Z, Mei S, Dong Y, She F, Li Y, Li P, Kong L. Functional Nanofibrous Biomaterials of Tailored Structures for Drug Delivery-A Critical Review. Pharmaceutics. 2020 ; 12(6):522.

72. Lim TC, Spector M. Biomaterials for enhancing CNS repair. Translational stroke research. 2017; 8(1):57-64.

73. Xing H, Lee H, Luo L, Kyriakides TR. Extracellular matrix-derived biomaterials in engineering cell function. Biotechnology advances. 2020; 42:107421.

74. Corti M, Calleri E, Perteghella S, Ferrara A, Tamma R, Milanese C, Mandracchia D, Brusotti G, Torre ML, Ribatti D, Auricchio F. Polyacrylate/polyacrylate-PEG biomaterials obtained by high internal phase emulsions (HIPEs) with tailorable drug release and effective mechanical and biological properties. Materials Science and Engineering: C. 2019; 105:110060.

75. Kim HS, Yun YH, Shim WG, Yoon SD. Preparation of atenolol imprinted polysaccharide based biomaterials for a transdermal drug delivery system. Journal of Drug Delivery Science and Technology. $2020 ; 59: 101893$.

76. Zhao J, Yin F, Ji L, Wang C, Shi C, Liu X, Yang H, Wang X, Kong L. Development of a Tau-Targeted Drug Delivery System Using a Multifunctional Nanoscale Metal-Organic Framework for Alzheimer's Disease Therapy. ACS Applied Materials \& Interfaces. 2020; 12(40):44447-58.

77. Shi S, Vissapragada R, Abi Jaoude J, Huang C, Mittal A, Liu E, Zhong J, Kumar V. Evolving role of biomaterials in diagnostic and therapeutic radiation oncology. Bioactive materials. 2020; $5(2): 233-40$.

78. Seah I, Zhao X, Lin Q, Liu Z, Su SZ, Yuen YS, Hunziker W, Lingam G, Loh XJ, Su X. Use of biomaterials for sustained delivery of antiVEGF to treat retinal diseases. Eye. 2020; 34(8):1341-56.

79. Li JA, Chen L, Zhang XQ, Guan SK. Enhancing biocompatibility and corrosion resistance of biodegradable Mg-Zn-Y-Nd alloy by preparing PDA/HA coating for potential application of cardiovascular biomaterials. Materials Science and Engineering: C. 2020; 109:110607.

80. Chen TY, Wen TK, Dai NT, Hsu SH. Cryogel/hydrogel biomaterials and acupuncture combined to promote diabetic skin wound healing through immunomodulation. Biomaterials 2021; 269:120608. 